\title{
Oil Palm Counting and Age Estimation from WorldView-3 Imagery and LiDAR Data Using an Integrated OBIA Height Model and Regression Analysis
}

\author{
Hossein Mojaddadi Rizeei, ${ }^{1}$ Helmi Z. M. Shafri ${ }^{D},{ }^{1}$ Mohamed Ali Mohamoud, ${ }^{1}$ \\ Biswajeet Pradhan (D, ${ }^{1,2}$ and Bahareh Kalantar ${ }^{1}$ \\ ${ }^{1}$ Department of Civil Engineering, Faculty of Engineering, Universiti Putra Malaysia, 43400 Seri Kembangan, Selangor, Malaysia \\ ${ }^{2}$ School of Systems, Management and Leadership, Faculty of Engineering and Information Technology, \\ University of Technology Sydney, Building 11, Level 0681 Broadway, P.O. Box 123, Ultimo, NSW 2007, Australia
}

Correspondence should be addressed to Biswajeet Pradhan; biswajeet24@gmail.com

Received 13 July 2017; Revised 23 October 2017; Accepted 20 November 2017; Published 8 January 2018

Academic Editor: Eduard Llobet

Copyright (c) 2018 Hossein Mojaddadi Rizeei et al. This is an open access article distributed under the Creative Commons Attribution License, which permits unrestricted use, distribution, and reproduction in any medium, provided the original work is properly cited.

\begin{abstract}
The current study proposes a new method for oil palm age estimation and counting from Worldview-3 satellite image and light detection and range (LiDAR) airborne imagery. A support vector machine algorithm (SVM) of object-based image analysis (OBIA) was implemented for oil palm counting. The sensitivity analysis was conducted on four SVM kernel types with associated segmentation parameters to obtain the optimal crown coverage delineation. Extracting tree's crown was integrated with height model and multiregression methods to accurately estimate the age of trees. The multiregression model with multikernel sizes was examined to achieve the most optimized model for age estimation. Applied models were trained and examined over five different oil palm plantations. The results of oil palm counting had an overall accuracy of $98.80 \%$, while the overall accuracy of age estimation showed $84.91 \%$, over all blocks. The relationship between tree's height and age was significant which supports the polynomial regression function (PRF) model with a $3 \times 3$ kernel size for under 10-12-year-old oil palm trees, while exponential regression function (ERF) is more fitted for older trees (i.e., 22 years old). Overall, recent remote sensing dataset and machine learning techniques are useful in monitoring and detecting oil palm plantation to maximize productivity.
\end{abstract}

\section{Introduction}

Oil palm is the second most significant source of vegetable oil after soybean $[1,2]$. Oil palm trees are widely planted in more than 43 countries between $10^{\circ} \mathrm{N}$ and $10^{\circ} \mathrm{S}$ of the equator. Production of palm oil at the expense of primary forest is of concern in Southeast Asia that offers provisioning and regulating bionetwork services [3]. Observing the oil palm characteristics in the plantation area is valuable to know for oil palm farmers and plantation stakeholders in order to maximize the productivity of planting [4]. Oil palm is one of the main economic crops in Malaysia making it the world's second largest area of oil palm producer after Indonesia in 2006 (http://www.palmoilworld.org). These two countries account about $64 \%$ of the total world production and $88 \%$ of global exports [5].

The varieties of palm oil are classified into two groups, namely, calm kernel oil and crude palm fruit oil. They are utilized in different applications such as food resources, the aloe-chemical industry, and biofuel sectors [6]. A twelvemonth period of global production of palm oil produces over 35 million metric tons, and $80 \%$ is coming from Indonesia and Malaysia [1]. The overall area under plantation is over 13.5 million hectares, the majority being under large scale 
plantation systems operating as a nucleus of many smallholders' products [7]. Age of oil palms is one of the vital issues which affects the fruit bunches. Maturity time of oil palm trees is around 3 years and it reaches its production peak between 6 to 10 years [8].

In the widely published literature, pixel-based classification was often used to classify feature classes from the images. However, it is very suitable to extract information based on the spectral signature of the object [9]. In more recent years, the object-based classification has been widely applied because of its ability to identify additional information such as the size, shape, texture, and also adjacent object occurrences related to the other [10]. More recently, the object-based image analysis (OBIA) method has evolved for fast analyzing of the high-resolution images [11]. With the growing availability of high-resolution and large-scale imagery, a new way of research on computer-based photointerpretation of trees was recently initiated [12]. Researchers have employed a parametric tree-crown surface model in which various features such as crown shape, illumination, and a sensor model are taken into consideration [13]. OBIA developed by Hay and Castilla is a discipline in spatial science that focuses on subdividing remote sensing images to meaning full objects through utilization of spatial and spectral properties [14]. The idea of analyzing an image in object space rather than in pixel space is developed due to insufficiencies of pixel-based methods, especially on high-resolution imageries. Moreover, object space has been reinforced in computational capacities and availabilities for analysis of high-resolution images such as IKONOS, GeoEye, and WorldView [11].

There are different methods to estimate the age of oil palm trees according to the previous literatures. One of the approaches is based on the relationship between radiance of individual image bands and derived vegetation indices to age at stand level. McMorrow [15] estimated the age of oil palms using radiance of Landsat Thematic Mapper (TM) at pixel and stand scales. They found a nonlinear negative relationship between spectral variables and age. Another method to estimate age is to use image classification algorithms to classify an image into discrete age categories or age classes [9]. Chemura et al. [16] developed a method to identify the age of oil palm plantations using WorldView- 2 and regression techniques. They used the relationship between age and crown area of oil palms using samples from the field, and they applied an object-based image analysis for classification. Tan et al. [17] investigated that the height data on oil palm trees have the potential to be used as one of the most important variables for studying their age. There is a strong correlation between height and age although diameter at breast height (DBH) shows weak correlation with age. It may be also possible to determine the age of oil palms using biophysical properties such as height and crown projection area [16].

In this paper, we propose a new method for oil palm tree counting and age estimation together, using WorldView-3 and LiDAR datasets. Two types of kernels (polynomial and radial bases) using the SVM object-based image analysis were applied on the WV-3 image to classify the oil palms from other features. The height model was extracted from LiDAR dataset and used to calculate the height of the trees. Multiregression models were applied to predict the age from the height model instead of crown size. In fact, the proposed model is a novel method for oil palm counting and age estimation and the experiment was tested on five unique study areas with different oil palm densities and ages. An accuracy assessment was carried out on each successfully segmented oil palm trees and estimated ages with regard to their respective ground truth data. By applying this method on current oil palm plantations, we can monitor, detect, and manage each individual tree more precisely which results in higher palm oil productivity. Hence, conversion of primary forest areas into new oil palm plantations would be reduced.

\section{Material and Methods}

Figure 1 shows the proposed oil palm tree counting and age estimation method from WorldView-3 and LiDAR dataset. First, three preprocessing steps were carried out for WorldView-3 dataset including geometric, atmospheric, and radiometric correction. In the current study, a pansharpened image was used to improve the spatial resolution of multispectral bands which can improve the delineation of trees. Then, an object-based image analysis was applied in two steps: segmentation and classification. The result of the classified objects was exported to GIS for further analysis. Last, the accuracy assessment and validation were conducted using field observation. On the other hand, LiDAR data processing was carried out to extract the digital surface model (DSM) and digital train model (DTM) from the point cloud data [18]. Then, height model was extracted with respect to two different kernel sizes, that is, $3 \times 3$ and $1 \times 1$, in order to detect the canopy cover and center of the trees, respectively. Moreover, three types of regression analysis (linear, polynomial, and exponential) were applied to establish the relationship between age and height of individual trees. Finally, the ages of the trees were validated based on filed observation.

2.1. Study Area. In this research, five blocks of oil palm plantation in the main campus of Universiti Putra Malaysia (UPM), located at latitude $\mathrm{N} 1^{\circ} 24^{\prime}$ to $\mathrm{N} 2^{\circ} 32^{\prime}$ and longitude $\mathrm{E} 102^{\circ} 42^{\prime}$ to $\mathrm{E} 103^{\circ} 38^{\prime}$, were selected as the case study (Figure 2). The UPM campus area covers about 1214 hectares while 121 hectares are administration buildings and the rest of the area is presently cultivated with many crops that include oil palms, orchards, pastures, and rubber trees.

2.2. Dataset. Two datasets were used from two sensors for this research, namely, WorldView-3 and LiDAR dataset. Wordview-3 was selected for oil palm detection and counting while the LiDAR dataset was used for age assessment as the height of the trees can be extracted using this dataset. The WorldView-3 satellite image was captured on September of 2015 over the project area of $20782 \times 14420$ pixels, geocoding lower left 410646.9/328776, and geocoding upper right $416881.5 / 333102$ according to the map datum Universal Transverse Mercator (UTM) zone $47^{\circ} \mathrm{N}$. WorldView-3 consists two types of high-resolution data images which are 


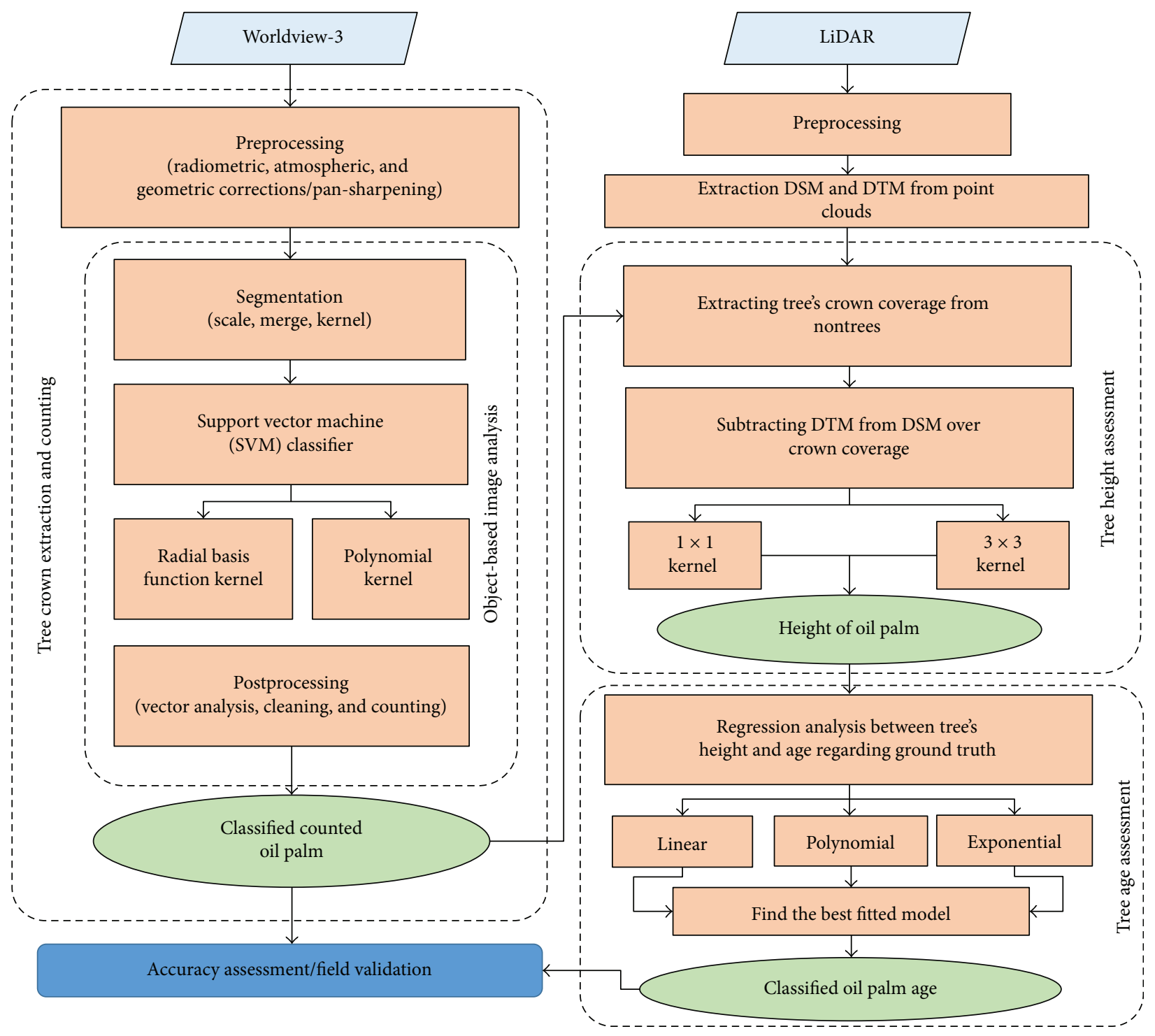

FIgURE 1: Overall methodological flowchart of this study.

panchromatic (PAN: $0.3 \mathrm{~m}$ spatial resolution) and multispectral (MS: $1.24 \mathrm{~m}$ spatial resolution). These band layers were fused together by the PAN-sharpening method to enhance the MS layers into a spatial resolution of 0.3 meters. Based on the present spatial resolution of color multispectral data, it is sufficient to detect the tree object. There are 8 multispectral bands which are coastal: $400-450 \mathrm{~nm}$, red: $630-690 \mathrm{~nm}$, blue: $450-510 \mathrm{~nm}$, red edge: $705-745 \mathrm{~nm}$, green: $510-$ $580 \mathrm{~nm}$, near-IR1: $770-895 \mathrm{~nm}$, yellow: $585-625 \mathrm{~nm}$, and near-IR2: $860-1040 \mathrm{~nm}$ in WorldView-3 while each band combinations are very useful to study on particular applications such as land use/land cover extraction [19] and tree species classification [20] studies.

Besides, LiDAR data point clouds were collected on November 2, 2015, with an Optech Airborne Laser Terrain Mapper 3100 instrument with a flying height of 1510 meters in a clear sky condition. The point density is closely 8 points per square meter with a $25,000 \mathrm{~Hz}$ pulse rate frequency. According to the point spacing, the data accuracy is $0.45 \mathrm{~m}$.

2.3. WV-3 Image Preprocessing. Preprocessing steps are required before using the WV-3 and LiDAR data. First, some initial processing was applied including geometric, atmospheric, and radiometric correction. The ATCOR (atmospheric and topographic correction) method was used for haze reduction and atmospheric and topographic correction [21]. Next, image digital numbers were converted to radiance and checked with some ground control points (GCPS) for performing radiometric and geometric correction, respectively. Hue saturation and value (HSV) image sharpening method was used to transform the WV-3 multispectral to the resolution of the panchromatic band [22]. After pan sharpening, the spatial resolution of the image increased to $0.3 \mathrm{~m}$ with the original number of bands which are eight. 

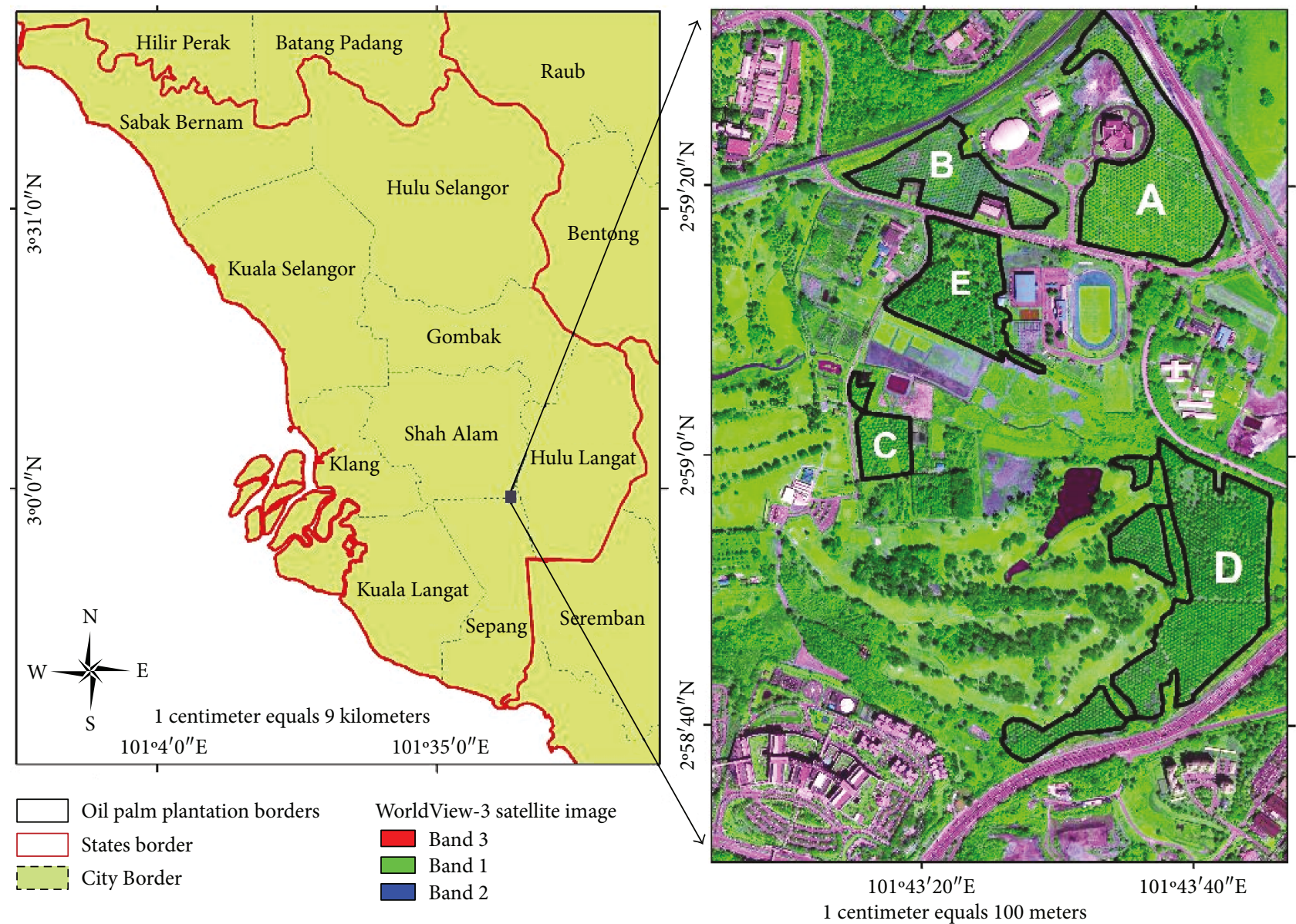

FIgURE 2: The location of five blocks of the study area.

2.4. LiDAR Preprocessing. LiDAR point clouds data should be first converted to LAS format and then filtered into first return and ground return to separate the surface from the train model, respectively. After that, they sampled into a regular grid and interpolated to yield DSM and DTM [23]. In this study, IDW which is a process of assigning values to unknown points by using values usually from a scattered set of known points was used [24]. The IDW interpolation method was used in this study because the set of points is dense (54 points per $\mathrm{m}^{2}$ ) which is good enough to capture the extent of local surface variation needed for the analysis.

2.5. Object-Based Image Analysis on WV-3. Object-based image analysis (OBIA) is intended to mimic human interpretation of remote sensing imagery and provide accurate and detailed spatial information that would normally take experienced people a long time to process although the roots of object-based analysis are linked to medical and industrial image analysis [11]. OBIA has shown a lot of potential of applications within remote sensing community. Object-based analysis involves two main steps: segmentation and classification [25].

To perform segmentation, image pixels are grouped into nonoverlapping homogenous regions based on some criteria.
In this study, the edge-based segmentation algorithm with three parameters, namely, scale level, merge level, and kernel, was applied [26]. Each plantation block has a different oil palm canopy coverage from others due to their oil palm age. So, there is no possibility to set a transferable segmentation for all the blocks. Hence, for each block, the optimal segmentation was set using the trial-and-error approach. In other words, the best values were defined via visual examination of the segmentation results. The selected values for the scale level, merge level, and algorithm are mentioned in Table 1.

After the segmentation process, several attributes were selected to be used as class predictors in the classification algorithm. From the spectral attributes, the four bands of the WV-3 image were selected. Choosing suitable training samples is one of the most important step of supervised classification approaches and can be highly essential in defining the final success of the classification results. The number of training samples were collected based on the number of spectral bands of the satellite image, the area of the plantation site, and the number of trees in each block [17, 27]. Basically, for block D, which is the biggest plantation area, more numbers of training data were selected (75) while for the small area of block $\mathrm{C}$, just 16 samples were collected to train the classifier model. Also, the numbers of the training 
TABLE 1: Classification and segmentation specification methods for all blocks.

\begin{tabular}{|c|c|c|c|c|c|c|c|c|c|c|}
\hline \multirow[b]{2}{*}{ Block } & \multicolumn{2}{|c|}{ Segment setting } & \multicolumn{2}{|c|}{ Merge setting } & \multirow{2}{*}{$\begin{array}{c}\text { Textural } \\
\text { kernel size }\end{array}$} & \multicolumn{5}{|c|}{ Classification algorithm } \\
\hline & Scale level & Algorithm & Merge level & Algorithm & & Method & Threshold & Type of kernel & $\begin{array}{l}\text { Gamma } \\
\text { in kernel }\end{array}$ & $\begin{array}{c}\text { Penalty } \\
\text { parameter }\end{array}$ \\
\hline$\overline{\mathrm{A}}$ & 5 & Edge & 80 & Full Lambda Schedule & 3 & SVM & 30 & Radial basis & 0.12 & 120 \\
\hline B & 5 & Edge & 87 & Full Lambda Schedule & 3 & SVM & 5 & Radial basis & 0.03 & 100 \\
\hline $\mathrm{C}$ & 10 & Edge & 90 & Full Lambda Schedule & 3 & SVM & 40 & Polynomial & 0.09 & 100 \\
\hline $\mathrm{D}$ & 3 & Edge & 95 & Full Lambda Schedule & 3 & SVM & 20 & Polynomial & 0.03 & 100 \\
\hline $\mathrm{E}$ & 5 & Edge & 93 & Full Lambda Schedule & 3 & SVM & 30 & Radial basis & 0.03 & 100 \\
\hline
\end{tabular}

samples, which was collected for blocks A, B, and E, were 59, 24 , and 31 , respectively. Training samples were selected randomly and well distributed for each blocks in order to avoid any spatial bias.

Example-based support vector machine (SVM) classifier was applied to perform the classification. Due to scope of this research, only two main classes were used, namely, oil palm and others (non-oil palm). SVM is a supervised learning binary classifier and is based on the structural risk minimization principle [28]. The nonlinear structures can be modeled by transferring the space of input data into high-dimension space through kernel trick [29].

The aim of the SVM classifier is to yield a model based on the training info which calculates the target values of the test sample [30, 31].

The kernel type selection in the SVM model can be considered as a vital step due to its direct impact on the successful training and classification accuracy [32].

The SVM model discovers a linear splitting hyperplane along with the maximal margin in the upper dimensional space. Generally, SVM algorithm deals with four basic kernels (e.g., linear, polynomial, sigmoid, and radial basis function).

In this research, the SVM classifier was conducted with all mentioned kernel types as well as the associated parameters for each block. To discover the most optimal results, the sensitivity analysis was performed regarding field counting observation. Threshold values were defined from 5 to 50 ; as the value of threshold was increased, the classifier allows more unclassified segments. While as the value of the threshold was reduced, SVM forces extra segments hooked on classes. The gamma $(\gamma)$ was arranged 0.03 to 0.125 , according to [33] the maximum gamma value should be an inverse of image spectral band number; since WV-3 has 8 bands, the value would be 0.125 . Moreover, the penalty factor $(c)$ was examined from 80 to 200.

Since the aim of applied object-based classification was to count the number of trees for each block, the optimal segmentation was set using the trial-and-error approach in which the possibility of selecting the optimal values is very high. Each plantation block has a different oil palm canopy coverage from others due to their different tree's age as well as variety of features (i.e., characteristics such as texture, size, etc.). So, using either semiautomatic or automatic segmentation methods which are needed to the features of the object itself ,causes difficulties to set the segmentation parameters. It means that not all the objects of interest will be considered due to the aforementioned reason. The selected values for the scale level, merge level, and algorithm are mentioned in Table 1.

After sensitivity analysis, the SVM algorithm with radial basis kernel showed the best discriminator with the related threshold, gamma, and penalty factors on A, B, and C blocks while polynomial kernel was the optimal kernel type with the following associated parameters to classify the features in blocks C and D (Table 1).

2.6. LiDAR Data Processing. To determine the tree heights, LiDAR point clouds were classified into two different categories. First, the bare earth or last returns, which represented the ground topography where points are reflected by the ground. DTM can be extracted from the last return. Secondly, the LiDAR first return indicates the surface of earth with all features where points are reflected by the features which covers the ground. DSM can be extracted from the first return. When the vegetation and the bare earth point clouds were categorized based on elevation above an ellipsoid, it is possible to generate the interpolated terrain models in raster format which allows calculating the height of trees. The height model is generated with subtracting DTM from DSM of LiDAR point cloud. After producing segmented images, it was exported to GIS environment to remove the undetected oil palm trees through postprocessing steps which included separation of the possible twin features and smoothing of the image objects. Then, using the attribute table, the extracted features were counted accurately.

Having classified the precise result of oil palm segmentation polygons, the LiDAR height model can be extracted using 1 by 1 (center point) and 3 by 3 (nine neighboring points) kernel pixel sizes to determine the accurate height of each individual tree. The results of the height models were then classified by using quintile classification into three classes (i.e., yellow color shows underestimated, green or blue color stands for well estimated, and red color indicates overestimated classes) to provide finer visual interpretation for further analysis as shown in Figure 3.

The height model was created from subtraction of DTM from DSM. Two different kernel sizes (i.e., $3 \times 3$ and $1 \times 1$ ) were applied to extract the minimum, maximum, and average of the height in the proposed model (Table 2). Then, three regression models were applied over five oil palm plantation blocks to implement the model. 


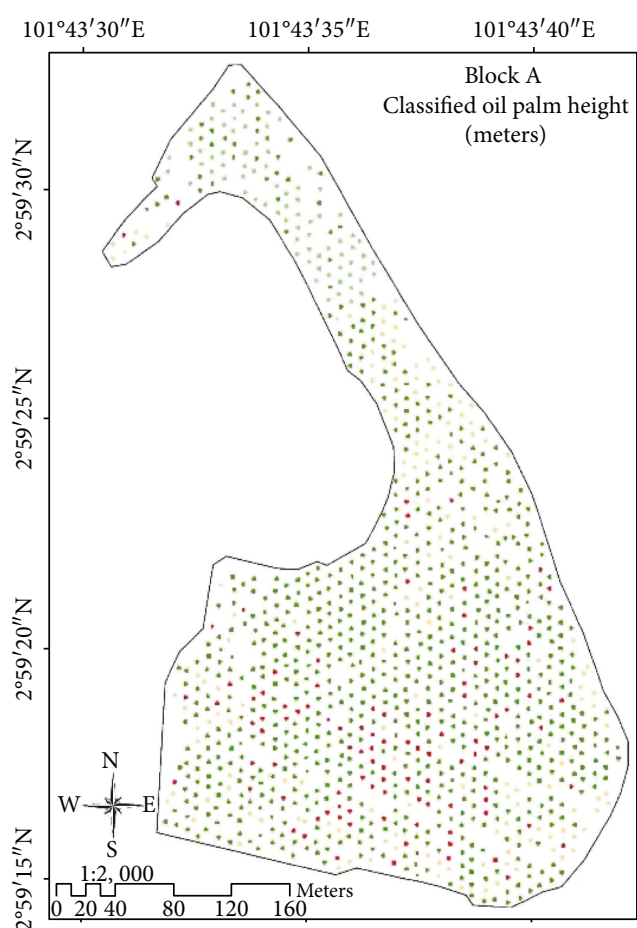

\begin{tabular}{|l}
$\square$ \\
$\square$ \\
$\square$ \\
$\square-5$ \\
$\square-6$
\end{tabular}
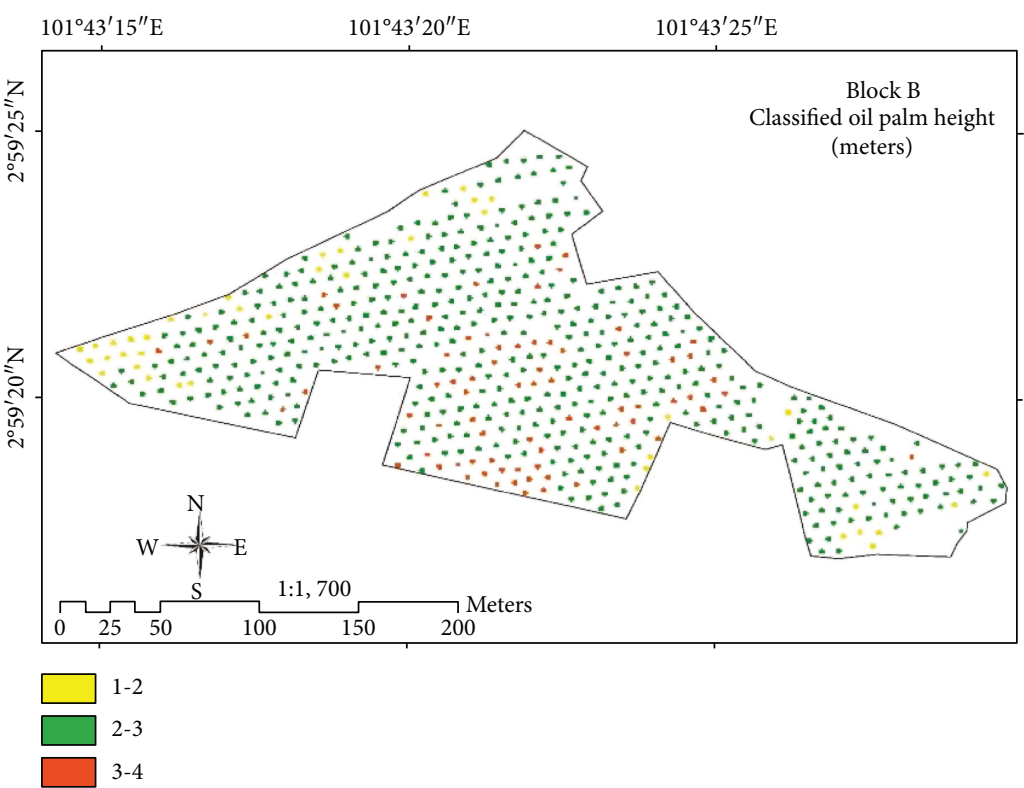

(a)
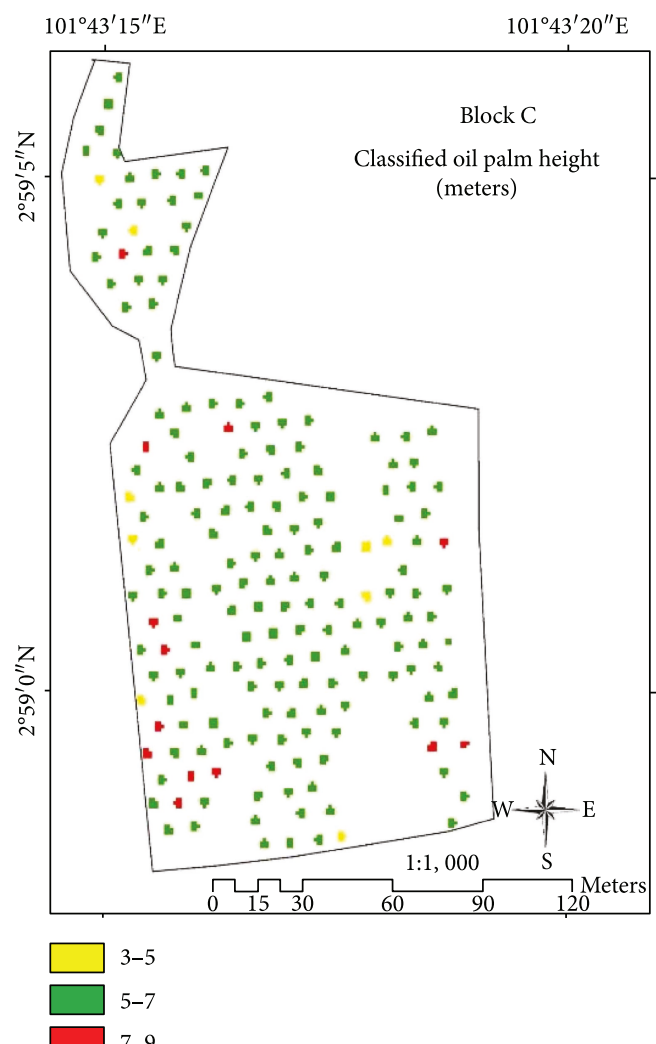

$3-5$
$5-7$
$7-9$

7-9 (b)

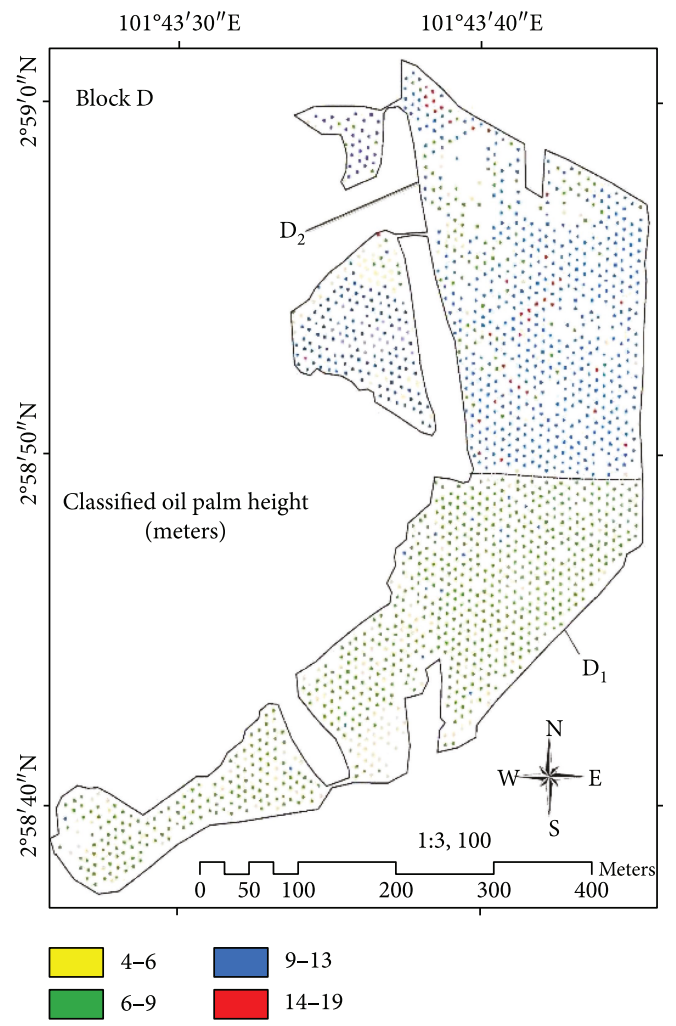

(d)

Figure 3: Continued. 


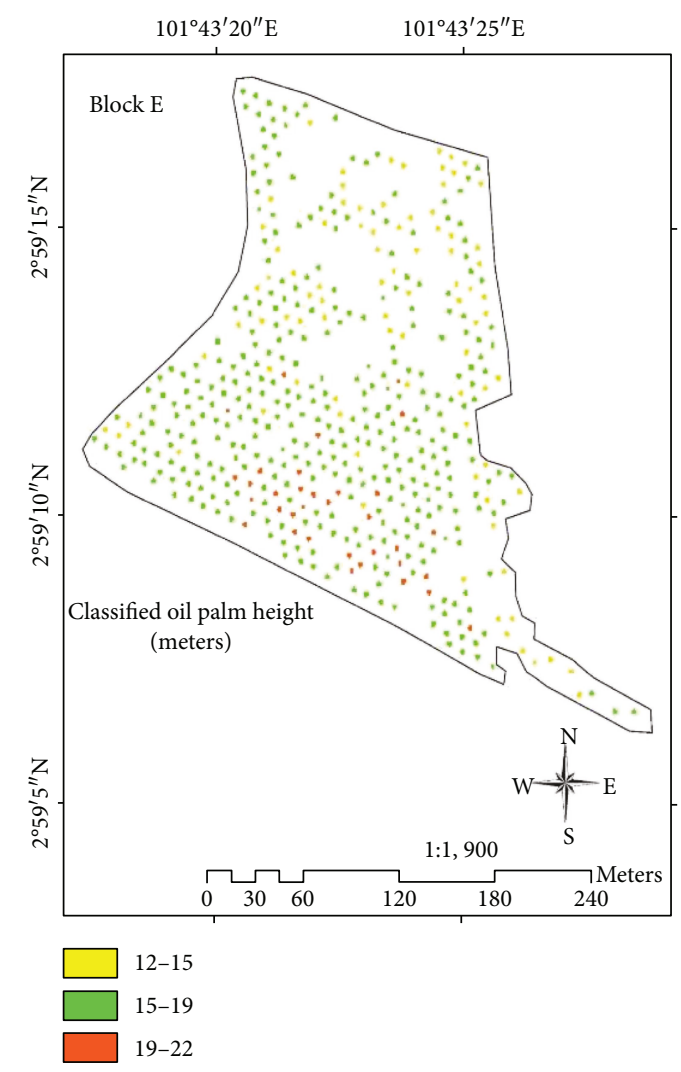

(e)

Figure 3: Classified height model for blocks A, B, C, D, and E.

TABLE 2: Age estimation analysis from different height and regression models examined over two kernel sizes.

\begin{tabular}{|c|c|c|c|c|c|c|c|c|}
\hline \multirow[b]{2}{*}{ Block } & \multirow[b]{2}{*}{ Number of pixels for each oil palm } & \multicolumn{3}{|c|}{ Height model } & \multirow[b]{2}{*}{$\begin{array}{c}\text { Actual } \\
\text { planted } \\
\text { age (year) }\end{array}$} & \multicolumn{3}{|c|}{ Regression models } \\
\hline & & $\begin{array}{c}\text { Min } \\
\text { height } \\
\text { (meters) }\end{array}$ & $\begin{array}{c}\text { Max } \\
\text { height } \\
\text { (meters) }\end{array}$ & $\begin{array}{c}\text { Average } \\
\text { height } \\
\text { (meters) }\end{array}$ & & $\begin{array}{l}\text { Linear } \\
(\mathrm{LRF})\end{array}$ & $\begin{array}{l}\text { Polynomial } \\
\quad(\mathrm{PRF})\end{array}$ & $\begin{array}{l}\text { Exponential } \\
\text { (ERF) }\end{array}$ \\
\hline \multirow{2}{*}{ A } & Single center point $(1 \times 1$ kernel $)$ & 0.1 & 6.17 & 3.71 & \multirow{2}{*}{4} & 3.50 & 3.76 & 5.21 \\
\hline & $3 \times 3$ kernel & 1.9 & 5.1 & 3.99 & & 3.81 & $4.08^{*}$ & 4.85 \\
\hline \multirow{2}{*}{ B } & Single center point $(1 \times 1$ kernel $)$ & 0.05 & 5.28 & 2.46 & \multirow{2}{*}{3} & 2.30 & 3.41 & 4.11 \\
\hline & $3 \times 3$ kernel & 1.5 & 3.55 & 2.65 & & 2.24 & $3.22^{*}$ & 3.80 \\
\hline \multirow[b]{2}{*}{$\mathrm{C}$} & Single center point $(1 \times 1$ kernel $)$ & 2.3 & 9.13 & 5.95 & \multirow{2}{*}{6} & 5.1 & 6.35 & 7.74 \\
\hline & $3 \times 3$ kernel & 3.7 & 7.01 & 5.6 & & 5.26 & $6.18^{*}$ & 7.31 \\
\hline \multirow{2}{*}{ D1 } & Single center point $(1 \times 1$ kernel $)$ & 2.4 & 10.80 & 8.23 & \multirow{2}{*}{8} & 7.60 & 8.85 & 10.5 \\
\hline & $3 \times 3$ kernel & 4.99 & 8.60 & 7.45 & & 9.07 & $8.13^{*}$ & 9.82 \\
\hline \multirow{2}{*}{$\mathrm{D} 2$} & Single center point $(1 \times 1$ kernel $)$ & 8.62 & 16.5 & 11.44 & \multirow{2}{*}{9} & 9.79 & 9.21 & 10.91 \\
\hline & $3 \times 3$ kernel & 8.62 & 14 & 10.23 & & 9.60 & $8.9^{*}$ & 10.66 \\
\hline \multirow{2}{*}{$\mathrm{E}$} & Single center point $(1 \times 1$ kernel $)$ & 4.85 & 21.55 & 15.30 & \multirow[b]{2}{*}{22} & 18.52 & 19.63 & 20.47 \\
\hline & $3 \times 3$ kernel & 12.52 & 18.95 & 16.03 & & 18.68 & 20.29 & $22.59^{*}$ \\
\hline
\end{tabular}

*The most accurate estimated age to actual age.

2.7. Field Observation and Validation. Field observation was performed to assess the accuracy of the estimated tree number and age in all study areas. The year of plantation and the number of oil palm trees planted in each block were collected. Table 3 shows the detailed information of each block. 
TABLE 3: Oil palm data collected from the field.

\begin{tabular}{lcccc}
\hline Block name & Planted year & Status & Number of trees & Area (ha) \\
\hline A & 2011 (4 years) & Productive & 1114 & 9.23 \\
B & 2012 (3 years) & Nonproductive & 584 & 4.57 \\
C & 2009 (5 year) & Productive & 183 & 1.92 \\
D & $2006 \& 2007$ (8 \& 9 years $)$ & Productive & 1731 & 14.77 \\
E & $1993(22$ years $)$ & Nonproductive & 474 \\
\hline
\end{tabular}

Subsequently, the precision/recall method, which is one of the well-known assessments [34], was implemented to evaluate tree counting accuracy. These equations provide a suitable means for predicting the age and height of each individual tree for most practical applications and could serve as a basis for descriptive or modeling work.

$$
\begin{aligned}
\text { Precision } & =\frac{\mathrm{TP}}{\mathrm{TP}+\mathrm{FP}}, \\
\text { Recall } & =\frac{\mathrm{TP}}{\mathrm{TP}+\mathrm{FN}}, \\
\text { F-measure } & =\frac{(1+\alpha) \times \text { precision } \times \text { recall }}{\alpha \times \text { precision }+ \text { recall }},
\end{aligned}
$$

where a true positive (TP) is the number of correctly detected oil palms. A false negative (FN) is an oil palm tree that is not detected. A false positive (FP) shows a pixel that is recognized as an oil palm tree but it is something else. $\alpha$ is a nonnegative scalar. In this study, $\alpha$ is set to 0.5 as suggested in [35]. Also, the success rate can be calculated by using another equation which is to determine the successful counted rate by dividing segmented numbers with total trees.

The best-fitted regression function for age estimation was also measured by the $R$-squared value [36]. The proposed method was evaluated using field observation for each block. Correlations between age and height were also implied.

ENVI 5.3 software was utilized to implement the first objective, that is, feature extraction, and ArcMap 10.3 software was used to analyze the data for counting of the oil palm trees by selection of attributes. The results of oil palm counting for all five blocks are shown in Figure 4.

2.8. Regression Analysis. Regression analysis has an ability to model and observe and discover spatial relationships between observed and simulated results. Also, this analysis defines the factors related to observe spatial patterns that can explain through it. Regressions provide a model from variables for age prediction. Multiple well-known regression models were applied in this part in order to evaluate the optimal OBIA kernel.

Three regression models, namely, linear regression function (LRF), polynomial regression function (PRF), and exponential regression function (ERF), were used to examine the correlations of height and age of oil palms in different study areas.

\section{Results and Discussion}

3.1. Oil Palm Counting. Möller [37] has suggested an object metric validation to assess the performance of image segmentation algorithm. Later, it was modified by Clinton [38] which specifically developed an assessment procedure for object-based segmentation problem. Their method was adapted in this paper to assess the individual delineated oil palm tree extracted from submeter resolution images. Only a successfully matched pair between the manually digitized training object and automatically developed segment objects was considered in this paper.

The main challenge of OBIA classification was separation of grass from oil palm and also separation of very dense canopy cover of oil palm trees from each other. By having the most optimized segmentation and SVM algorithm, the best classification result enabled us to count the trees precisely. It was believed that the imperfect pixel masking is the reason why full capacities of segment generation cannot be achieved. Subsequently, the remaining trees are then evaluated accordingly based on their coincided area and centroid gap distance between the manually digitized training object and automatically developed segment object.

The results showed that young oil palm tree plantations (between the age of 4 to 6 years) have very accurate segmentation results; however, older oil palm plantations could not be delineated accurately by the segmentation process due to the mixed tree's coverage in most parts of the plantation.

The individual crown of oil palm can be determined using object-based analysis and the obtained crown can be used for counting and predicting the age of oil palms at field level. However, many factors have affected the delineation accuracy; one of the most significant factors which was found in this study was stand characteristic under growth. The density of undergrowth differs in each field, and stand level approach was found most suitable than the delineation of the whole image.

3.2. Oil Palm Age Estimation. The age detection algorithm was applied to LiDAR data to estimate the age from the height model instead of crown size.

Overall assessment between different heights of oil palm with field-observed ages over five plantation blocks showed that trees with the same range of height have a relevant similar age in the study areas. This was the initial bright rationale, to test our integrated model for age estimation based on tree's height. In fact, there are many parameters which affect the oil palm growth either negatively or positively, that is, soil type, watering duration, and fertilization. However, in this research, all the blocks were treated similarly in terms of irrigation procedure, fertilization materials, and soil suitability. By using the average weight method over 

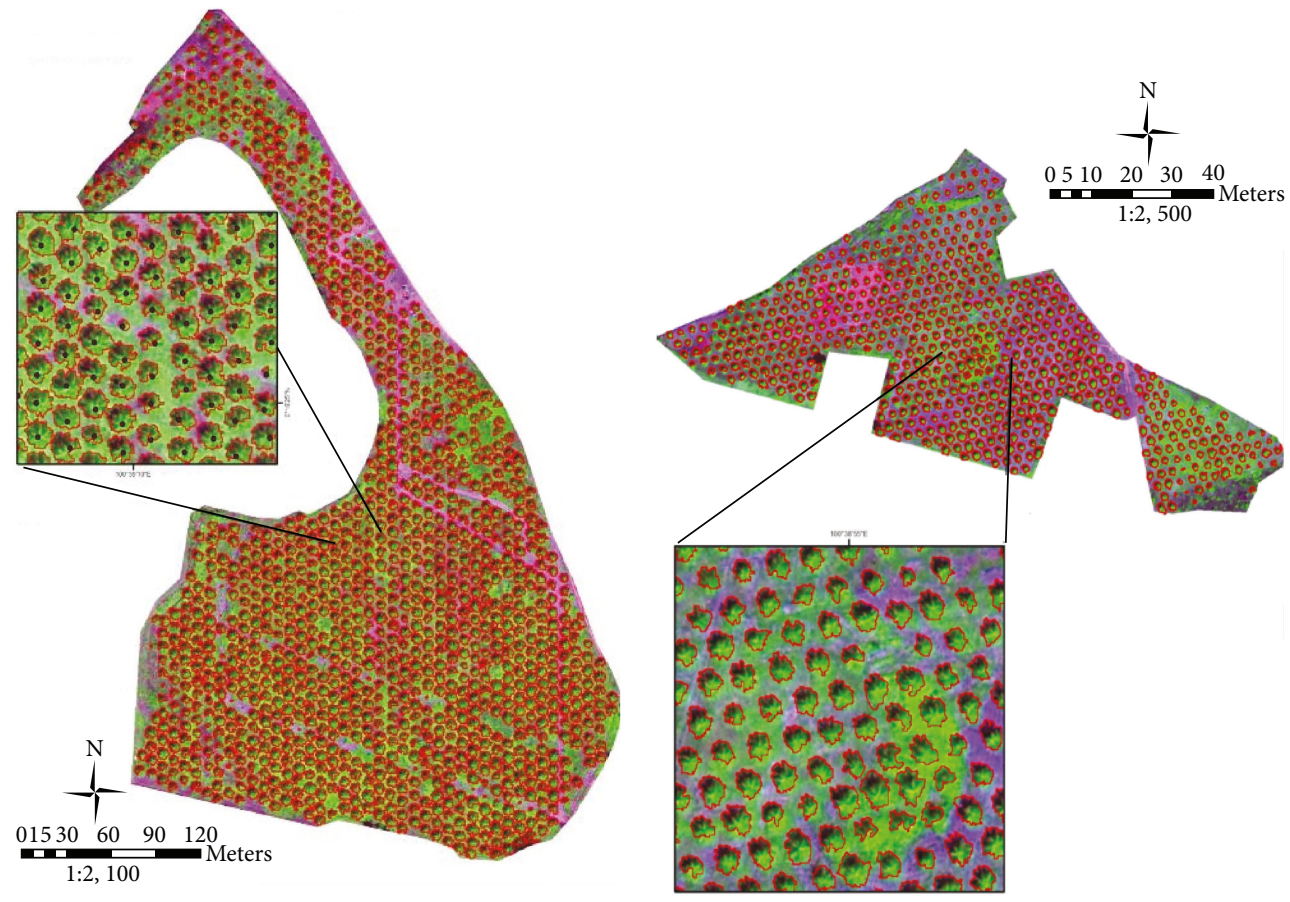

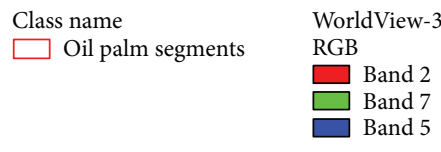

(a)
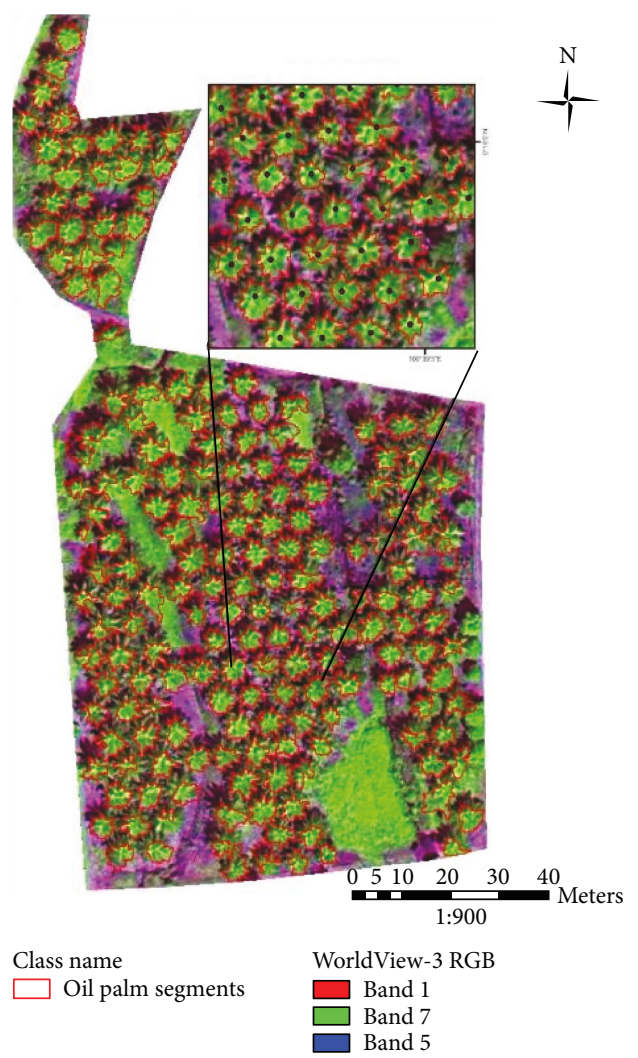

(c)

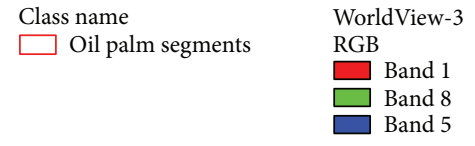

(b)

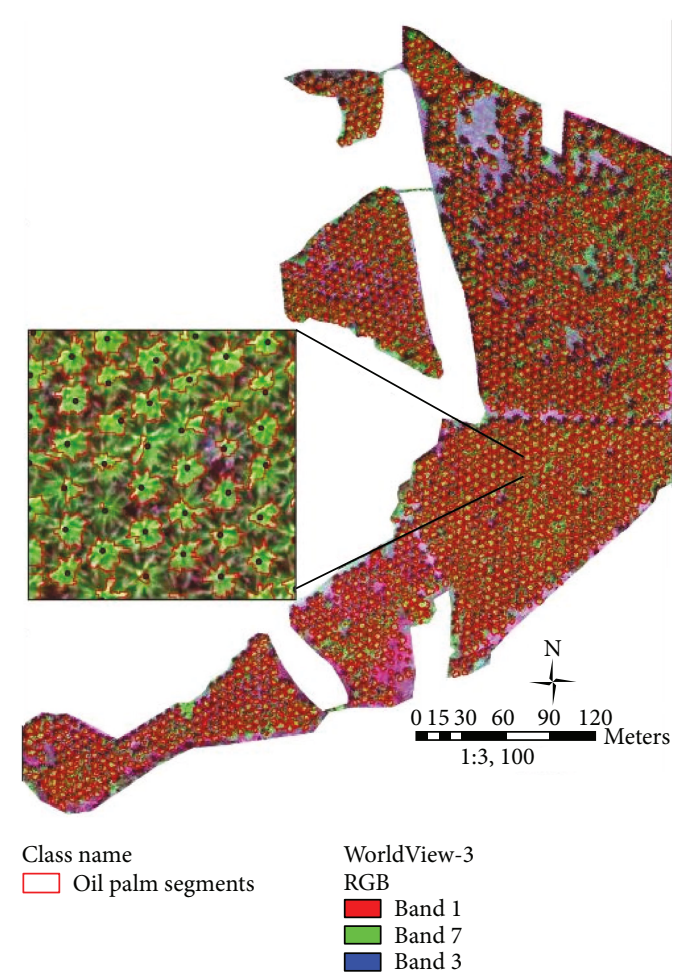

(d)

Figure 4: Continued. 


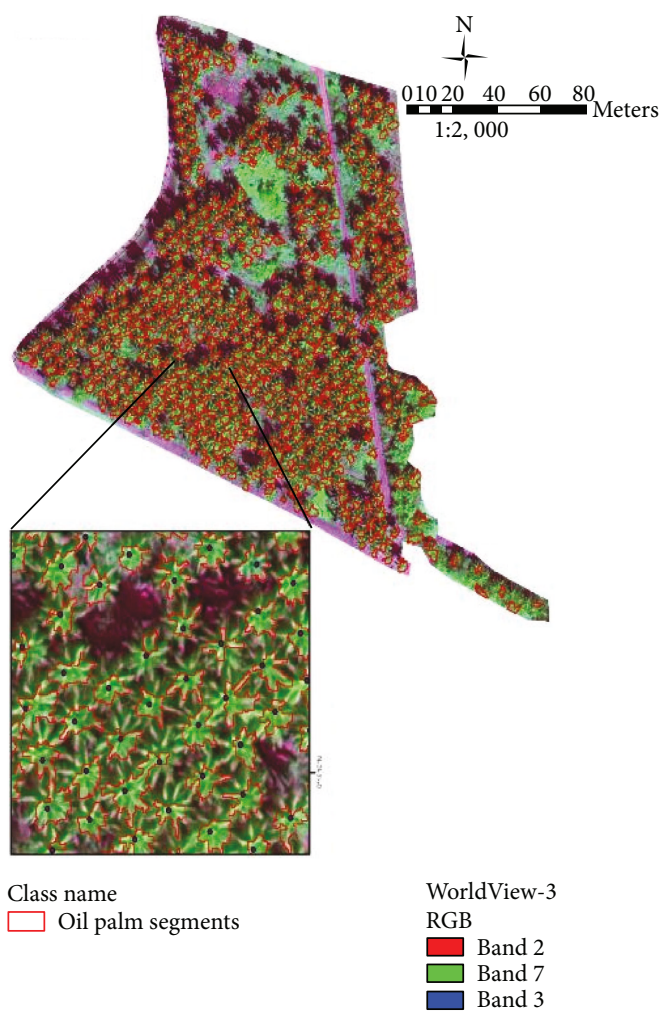

(e)

Figure 4: Classified oil palm detection maps for blocks A, B, C, D, and E

4036 trees, approximate ages for related tree's height were estimated. Therefore, the mentioned parameters were ignored. Table 4 shows the relation of oil palm height with observed ages.

Using dependent (height) and independent (age) variables for the entire study areas, three regression models were developed to discover the correlation between variables as shown in Table 5. Regression models then are applied in every segmented oil palm with different kernel sizes for each block in order to estimate the most optimal tree age.

According to Table 2 it can be clearly seen that the $3 \times 3$ kernel size shows much precise measurement rather than the single center point of oil palms. PRF more accurately performed in estimation of tree age rather than LRF and ERF. Specifically, PRF was the ideal age estimation model for the actual oil palm age in blocks $\mathrm{A}, \mathrm{B}, \mathrm{C}$, and D, while ERF was perfectly projected for block E. LRF, however, had an acceptable correlation values in all blocks. Figures 5 and 6 illustrate the most fitted regression models for each block graphically. The reason is because of the age stage structure and nature of oil palm growth. Technically speaking, due to the nature of oil palms, in young trees (i.e., almost less than 10-12 years), height horizontal growth is faster than crown canopy growth; however, after almost 10-12 years, increase of tree's height gradually would be slow. Hence, PRF had an accurate estimation among young trees (i.e., less than 10-12 years old) while it underestimated the age of 22 -year-old trees planted in block $\mathrm{E}$.
TABLE 4: Relative oil palm height with field-observed ages from all blocks.

\begin{tabular}{lccc}
\hline Height (meters) & Age (year) & Height (meters) & Age (year) \\
\hline 1 & 3 & 11 & 9 \\
2 & 3 & 12 & 9 \\
3 & 3.5 & 13 & 15.5 \\
4 & 5 & 14 & 22 \\
5 & 6 & 15 & 22 \\
6 & 7 & 16 & 22 \\
7 & 7 & 17 & 22 \\
8 & 8 & 18 & 22 \\
9 & 8 & 19 & 22 \\
10 & 9 & & \\
\hline
\end{tabular}

TABLE 5: Initial regression of oil palm height with field-observed age using regression models.

\begin{tabular}{lcc}
\hline Regression models & Correlation methods & $R^{2}$ \\
\hline LRF & $Y=1.2803 x-0.9951$ & 0.88 \\
PRF & $Y=0.0404 x 2+0.4605 x+1.9856$ & 0.91 \\
ERF & $Y=2.8103 e 0.1218 x$ & 0.90 \\
\hline
\end{tabular}

3.3. Validation of Oil Palm Counting. The results showed a considerable variation in height within age classes, particularly for younger trees (i.e., under 10 to 12 years old). Yet, 


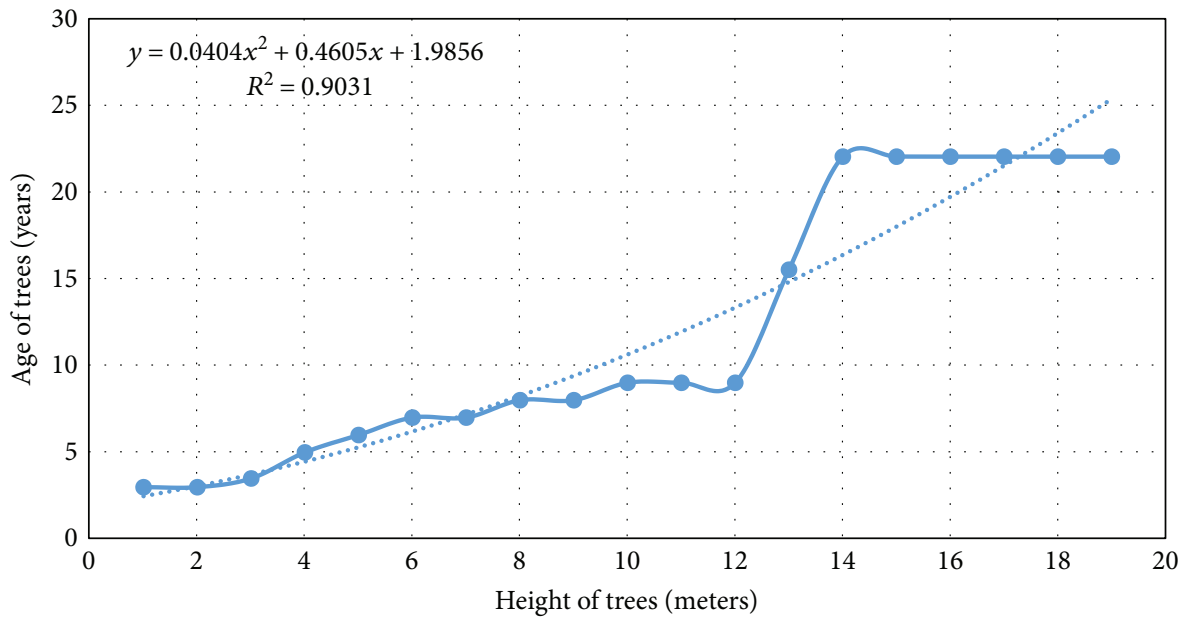

FIgURE 5: Optimal fitted PRF for age estimation of blocks A, B, C, and D.

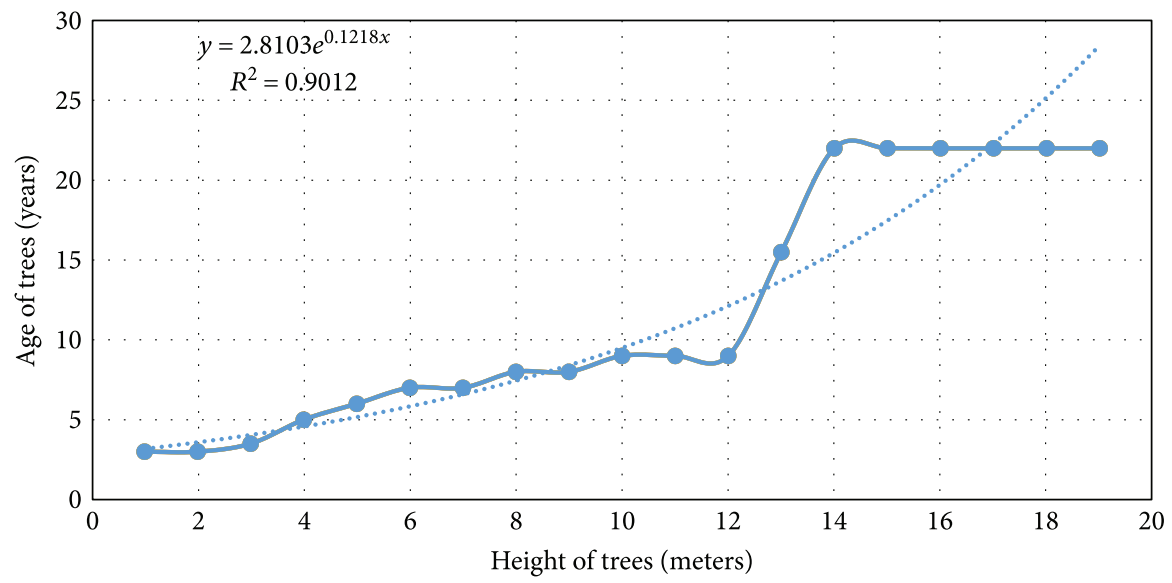

Figure 6: Optimal fitted ERF for age estimation of block E.

despite of variability associated with the tree age and crown, the number of counted trees was precisely accurate.

Table 6 shows the results of the SVM object-based image analysis which resulted in very high accuracy for all blocks. The calculated F-measure index shows the accuracy. Blocks B, C, and D show the excellent (above 99\%) accuracy in classification which are followed by blocks A and E (approximately 98 and $97.5 \%$, resp.). This achievement in tree counting is higher than other current techniques in which oil palms were counted from high spatial resolution airborne imagery data with $95 \%$ and $97 \%$ accuracy $[5,39]$.

Therefore, the applied classification method can be transferrable to any other oil palm plantation with the same climate and condition.

3.4. Validation of Oil Palm Age Estimation. Basically, the applied method showed high precision in all blocks (approximately $85 \%$ in overall accuracy) which is a substantial result in oil palm age estimation studies. We compared our results with those reported in literature and observed that; for instance, [16] used WV-2 to detect canopy crown of oil palm which calibrated with regression
TABLE 6: Oil palm counting accuracy assessment result.

\begin{tabular}{lccccc}
\hline Pilot study areas & $\begin{array}{c}\text { Block } \\
\text { A }\end{array}$ & $\begin{array}{c}\text { Block } \\
\text { B }\end{array}$ & $\begin{array}{c}\text { Block } \\
\text { C }\end{array}$ & $\begin{array}{c}\text { Block } \\
\text { D }\end{array}$ & $\begin{array}{c}\text { Block } \\
\text { E }\end{array}$ \\
\hline $\begin{array}{l}\text { Actual counted } \\
\text { trees }\end{array}$ & 1114 & 584 & 183 & 1731 & 474 \\
Estimated trees & 1141 & 575 & 185 & 1705 & 440 \\
FP & 27 & 0 & 2 & 0 & 0 \\
FN & 5 & 9 & 0 & 26 & 34 \\
TP & 1114 & 575 & 183 & 1705 & 440 \\
Precision & 0.98 & 1.00 & 0.99 & 1.00 & 1.00 \\
Recall & 1.00 & 0.98 & 1.00 & 0.98 & 0.93 \\
F-measure & 0.9827 & 0.9948 & 0.9928 & 0.9949 & 0.9749 \\
\hline
\end{tabular}

models to estimate oil palm ages. Their results indicated just $27.9 \%$ of the fields accurately estimated and the rest of trees had an estimation error of 1 to 2 years. Also, [17] integrated optical satellite image of UK-DMC with active ALOS PALSAR imagery for the same analysis. They demonstrated good correlation of 4.9 to 0.76 with the age of oil palm trees. 
TABLE 7: Oil palm age estimation accuracy assessment result.

\begin{tabular}{lccccc}
\hline Block & \multicolumn{2}{c}{ Range of } \\
height $(\mathrm{m})$ & $\begin{array}{c}\text { Number of } \\
\text { well-estimated }\end{array}$ & $\begin{array}{c}\text { Total } \\
\text { number }\end{array}$ & $\begin{array}{c}\text { Accuracy } \\
(\%)\end{array}$ \\
\hline From & To & age & & \\
B & 3 & 5 & 998 & 1136 & 87.9 \\
C & 2 & 3 & 526 & 584 & 90.1 \\
D1 & 5 & 7 & 161 & 183 & 88.0 \\
D2 & 6 & 9 & 780 & 890 & 87.6 \\
E & 9 & 13 & 665 & 841 & 79.1 \\
\hline
\end{tabular}

"Single tree's age would not be expected accurately at the pixel or stand scales" [15]. They aggregated the oil palm classes and resulted in RMS errors down to $5.8 \%$ which were acquired by using IRIsq [15].

For each block, we obtained a different accuracy rate that is mainly due to tree age discriminations as shown in Table 7. The proper tree height range and estimated age of each block strongly support the regression models. Accordingly, there is a significant correlation between estimated age and tree height in the study areas. Specifically, the integrated OBIA height model with regression functions is a successful method to estimate the age of oil palms up to $90 \%$. The applied model showed higher precision for trees under 10-12 years old, whilst, in block E, the accuracy was not very outstanding (almost 77\%) due to the existence of old-aged trees.

\section{Conclusion}

Oil palm counting and age estimation are crucial tasks for oil palm plantation management. Oil palm trees have certain amounts of product (palm oil) in their different ages. Besides, tree counting is an important practice for monitoring and replanting. Thus, knowing the number of trees and their ages can estimate the future palm oil yield. As manual observation is very time consuming, expensive, and not accurate in large scale, remote sensing approach is used. In the most previous studies, the canopy cover is used for age estimation. In that case, not only the accuracy might be reduced due to mixed crown canopy with neighbor's coverage but also the methods are hardly transformable to other study areas. Thus, in order to improve the previous methods, the presented models are developed. It was aimed to extract the polygon of individual oil palm trees by a new integrated approach from WorldView-3 and LiDAR datasets. Although segmentation of oil palm trees in different age was very complicated due to interference of leaf coverage, the optimal segmentation parameters were achieved by the trial-and-error method.

Based on sensitivity analysis, two SVM kernel types (polynomial and radial basis) with optimized associated parameters, namely, gamma $(\gamma)$ and penalty $(c)$ factors, showed the highest capability to classify and count the individual oil palm trees. This classification method achieved nearly $99 \%$ detection of total trees inside the plantation area.
The tree height was determined using the precise result of oil palm segmentation polygons. The LiDAR height model was applied on $3 \times 3$ kernel pixels extracted from oil palm segmentation. Further, three regression functions were implemented to discover the most fitted correlations between height and age of trees. Assessed accuracy strongly supported PRF as ideal model for age estimation in blocks A, B, C, and $\mathrm{D}$ compared with real oil palm age; however, just in block E, ERF was the best fitted curve because of the older age stage and mixed canopy coverage of trees.

The age estimation approach demonstrated in this research depends on precise delineation of oil palm crowns which can be achieved by integration of very highresolution datasets. Also, it is transferable to other similar study areas. The proposed method was developed that enables the agricultural decision makers to precisely monitor, detect, and manage oil palm plantations.

\section{Conflicts of Interest}

The authors declare that there is no conflict of interest regarding the publication of this paper.

\section{References}

[1] E. Fitzherbert, M. Struebig, A. Morel et al., "How will oil palm expansion affect biodiversity?," Trends in Ecology \& Evolution, vol. 23, no. 10, pp. 538-545, 2008.

[2] I. A. W. Tan, A. L. Ahmad, and B. H. Hameed, "Adsorption isotherms, kinetics, thermodynamics and desorption studies of 2,4,6-trichlorophenol on oil palm empty fruit bunch-based activated carbon," Journal of Hazardous Materials, vol. 164, no. 2-3, pp. 473-482, 2009.

[3] R. Härdter, W. Y. Chow, and O. S. Hock, "Intensive plantation cropping, a source of sustainable food and energy production in the tropical rain forest areas in Southeast Asia," Forest Ecology and Management, vol. 91, no. 1, pp. 93-102, 1997.

[4] J. M. McMorrow, "Relation of oil palm spectral response to stand age," International Journal of Remote Sensing, vol. 16, no. 16, pp. 3203-3209, 1995.

[5] H. Z. M. Shafri, N. Hamdan, and M. I. Saripan, "Semi-automatic detection and counting of oil palm trees from high spatial resolution airborne imagery," International Journal of Remote Sensing, vol. 32, no. 8, pp. 2095-2115, 2011.

[6] Y. Basiron, "Palm oil production through sustainable plantations," European Journal of Lipid Science and Technology, vol. 109, no. 4, pp. 289-295, 2007.

[7] R. A. Butler, L. P. Koh, and J. Ghazoul, "REDD in the red: palm oil could undermine carbon payment schemes," Conservation Letters, vol. 2, no. 2, pp. 67-73, 2009.

[8] P. Srestasathiern and P. Rakwatin, "Oil palm tree detection with high resolution multi-spectral satellite imagery," Remote Sensing, vol. 6, no. 10, pp. 9749-9774, 2014.

[9] P. S. Thenkabail, N. Stucky, B. W. Griscom et al., "Biomass estimations and carbon stock calculations in the oil palm plantations of African derived savannas using IKONOS data," International Journal of Remote Sensing, vol. 25, no. 23, pp. 5447-5472, 2004.

[10] A. Korom, M. H. Phua, Y. Hirata, and T. Matsuura, "Extracting oil palm crown from WorldView-2 satellite image," IOP 
Conference Series: Earth and Environmental Science, vol. 18, article 12188, 2014.

[11] T. Blaschke, "Object based image analysis for remote sensing," ISPRS Journal of Photogrammetry and Remote Sensing, vol. 65, no. 1, pp. 2-16, 2010.

[12] P. Gong, G. S. Biging, S. M. Lee et al., "Photo ecometrics for forest inventory," Geographic Information Sciences, vol. 5, no. 1, pp. 9-14, 1999.

[13] L. Wang, P. Gong, and G. S. Biging, "Individual tree-crown delineation and treetop detection in high-spatial-resolution aerial imagery," Photogrammetric Engineering \& Remote Sensing, vol. 70, no. 3, pp. 351-357, 2004.

[14] G. J. Hay and G. Castilla, "Geographic object-based image analysis (GEOBIA): a new name for a new discipline," in Object-Based Image Analysis, pp. 75-89, Springer, Berlin Heidelberg, 2008.

[15] J. McMorrow, "Linear regression modelling for the estimation of oil palm age from Landsat TM," International Journal of Remote Sensing, vol. 22, no. 12, pp. 2243-2264, 2001.

[16] A. Chemura, I. van Duren, and L. M. van Leeuwen, "Determination of the age of oil palm from crown projection area detected from WorldView-2 multispectral remote sensing data: the case of Ejisu-Juaben district, Ghana," ISPRS Journal of Photogrammetry and Remote Sensing, vol. 100, pp. 118127, 2015.

[17] K. P. Tan, K. D. Kanniah, and A. P. Cracknell, "Use of UKDMC 2 and ALOS PALSAR for studying the age of oil palm trees in southern Peninsular Malaysia," International Journal of Remote Sensing, vol. 34, no. 20, pp. 7424-7446, 2013.

[18] M. R. Mezaal, B. Pradhan, M. I. Sameen, H. Z. Mohd Shafri, and Z. M. Yusoff, "Optimized neural architecture for automatic landslide detection from high-resolution airborne laser scanning data," Applied Sciences, vol. 7, no. 7, p. 730, 2017.

[19] H. M. Rizeei, M. A. Saharkhiz, B. Pradhan, and N. Ahmad, "Soil erosion prediction based on land cover dynamics at the Semenyih watershed in Malaysia using LTM and USLE models," Geocarto International, vol. 31, no. 10, pp. 11581177, 2016.

[20] D. Li, Y. Ke, H. Gong, and X. Li, “Object-based urban tree species classification using bi-temporal WorldView-2 and WorldView-3 images," Remote Sensing, vol. 7, no. 12, pp. 16917-16937, 2015.

[21] R. Richter and D. Schläpfer, ATCOR-4 User Guide, Vol. 7.0.3, Wessling, Germany, 2005.

[22] J. C. Russ and R. P. Woods, "The image processing handbook, 2nd Ed," Journal of Computer Assisted Tomography, vol. 19, no. 6, pp. 979-981, 1995.

[23] L. Chen, S. Zhao, W. Han, and Y. Li, "Building detection in an urban area using LiDAR data and QuickBird imagery," International Journal of Remote Sensing, vol. 33, no. 16, pp. 5135-5148, 2012.

[24] B. Pradhan, "Landslide susceptibility mapping of a catchment area using frequency ratio, fuzzy logic and multivariate logistic regression approaches," Journal of the Indian Society of Remote Sensing, vol. 38, no. 2, pp. 301-320, 2010.

[25] T. Blaschke and S. Lang, "Object-based image analysis for automated information extraction-a synthesis," in Measuring the Earth II ASPRS Fall Conference, pp. 6-10, San Antonio, TX, USA, 2006.

[26] T. Blaschke, C. Burnett, and A. Pekkarinen, "Image segmentation methods for object-based analysis and classification," in
Remote Sensing Image Analysis: Including the Spatial Domain, Vol. 211-236, pp. 211-236, Springer, Dordrecht, Netherlands, 2004.

[27] R. M. McCoy, Field Methods in Remote Sensing, Guilford Press, New York, NY, USA, 2005.

[28] V. Vapnik, The Nature of Statistical Learning Theory, Springer, New York, NY, USA, 2013.

[29] M. N. Jebur, B. Pradhan, and M. S. Tehrany, "Optimization of landslide conditioning factors using very high-resolution airborne laser scanning (LiDAR) data at catchment scale," Remote Sensing of Environment, vol. 152, pp. 150-165, 2014.

[30] C. W. Hsu, C. C. Chang, and C. J. Lin, A Practical Guide to Support Vector Classification, Technical Report, Department of Computer Science and Information Engineering, National Taiwan University, 2003.

[31] H. Mojaddadi, B. Pradhan, H. Nampak, N. Ahmad, and A. H. bin Ghazali, "Ensemble machine-learning-based geospatial approach for flood risk assessment using multi-sensor remote-sensing data and GIS," Geomatics, Natural Hazards and Risk, vol. 8, no. 2, pp. 1080-1102, 2017.

[32] C. J. C. Burges, "A tutorial on support vector machines for pattern recognition," Data Mining and Knowledge Discovery, vol. 2, no. 2, pp. 121-167, 1998.

[33] M. Ustuner, F. B. Sanli, and B. Dixon, "Application of support vector machines for landuse classification using highresolution RapidEye images: a sensitivity analysis," European Journal of Remote Sensing, vol. 48, no. 1, pp. 403-422, 2015.

[34] R. Nyland, Silviculture: Concepts and Applications, McGrawHill, New York, NY, USA, 1996.

[35] T. Liu, Z. Yuan, J. Sun et al., "Learning to detect a salient object," IEEE Transactions on Pattern Analysis and Machine Intelligence, vol. 33, no. 2, pp. 353-367, 2011.

[36] A. Jmp and M. Proust, Modeling and Multivariate Methods, JMP Inc., Cary, NC, USA, 2012.

[37] M. Möller, L. Lymburner, and M. Volk, "The comparison index: a tool for assessing the accuracy of image segmentation," International Journal of Applied Earth Observation and Geoinformation, vol. 9, no. 3, pp. 311-321, 2007.

[38] N. Clinton, A. Holt, J. Scarborough, L. Yan, and P. Gong, "Accuracy assessment measures for object-based image segmentation goodness," Photogrammetric Engineering \& Remote Sensing, vol. 76, no. 3, pp. 289-299, 2010.

[39] M. J. Falkowski, A. M. S. Smith, A. T. Hudak, P. E. Gessler, L. A. Vierling, and N. L. Crookston, "Automated estimation of individual conifer tree height and crown diameter via two-dimensional spatial wavelet analysis of LiDAR data," Canadian Journal of Remote Sensing, vol. 32, no. 2, pp. 153161, 2006. 


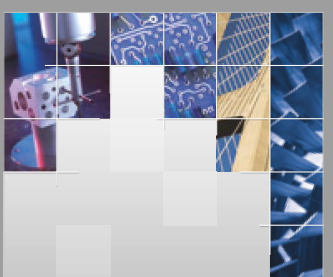

\section{Enfincering}
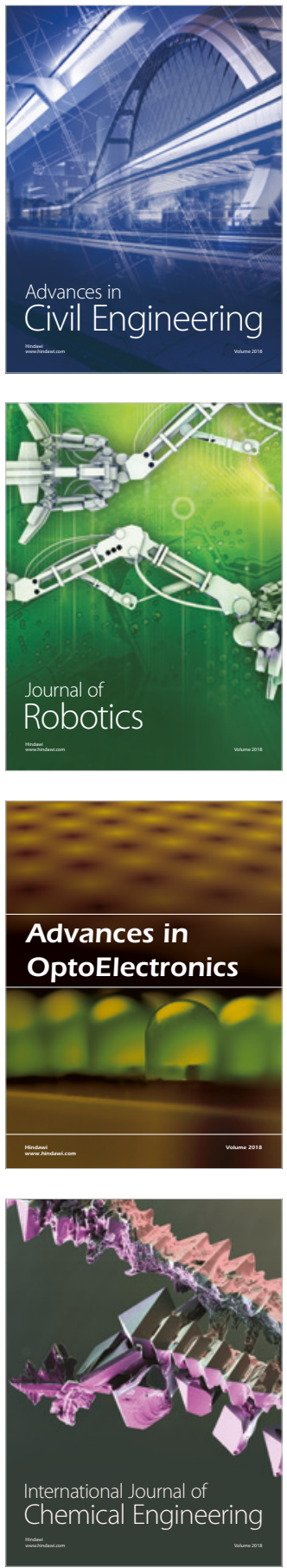

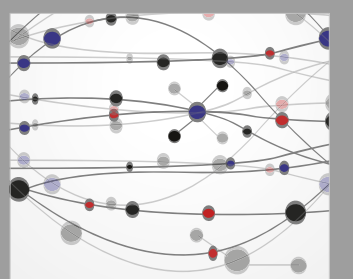

\section{Rotating \\ Machinery}

The Scientific World Journal

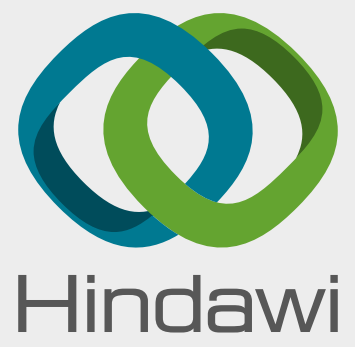

Submit your manuscripts at

www.hindawi.com
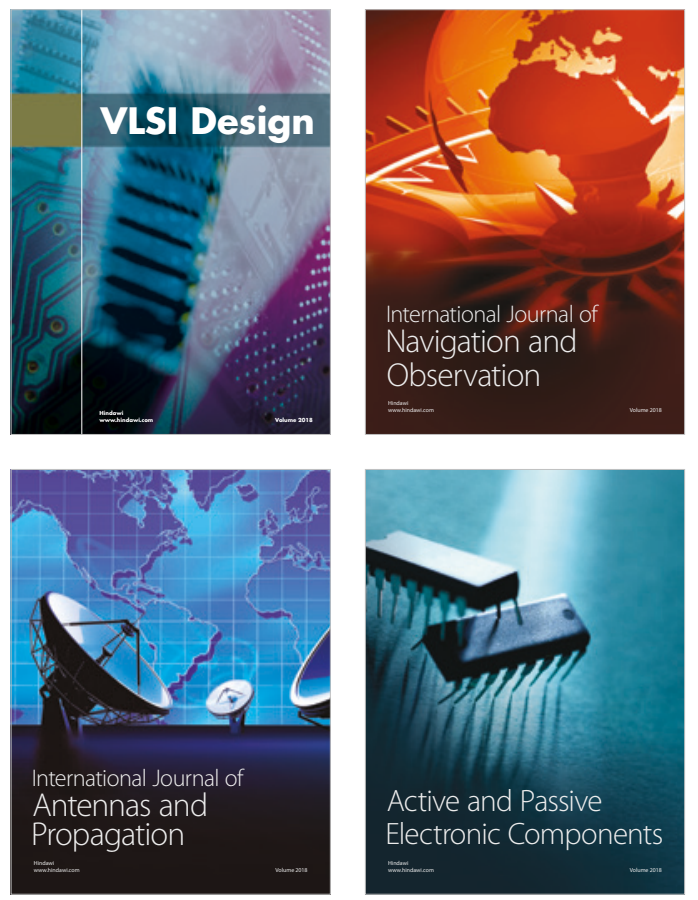
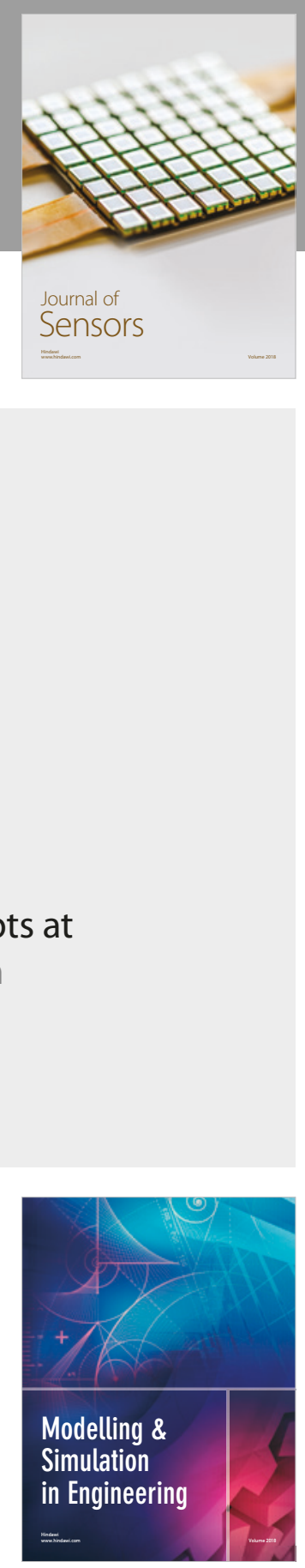

\section{Advances \\ Multimedia}
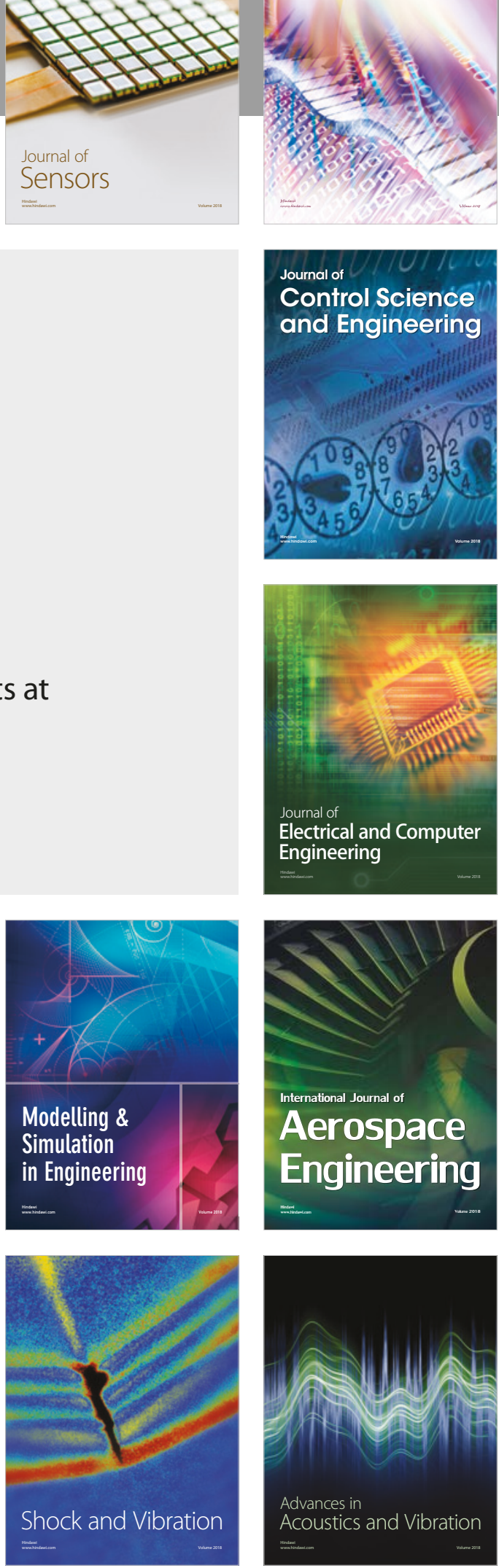